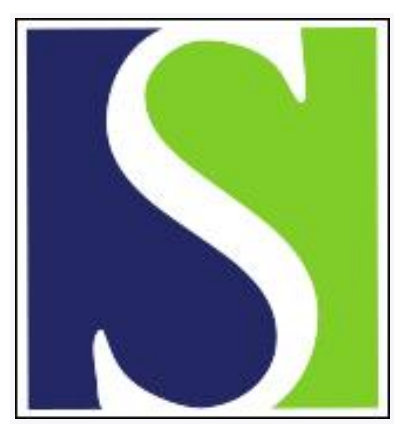

Scand J Work Environ Health 1993;19(5):319-325

https://doi.org/10.5271/sjweh.1468

Issue date: 01 Oct 1993

Impact of regular relaxation training on the cardiac autonomic nervous system of hospital cleaners and bank employees.

by Toivanen H, Lansimies E, Jokela V, Hanninen $\mathrm{O}$

Affiliation: Department of Physiology, University of Kuopio, Finland.

This article in PubMed: www.ncbi.nlm.nih.gov/pubmed/8296180 


\title{
Impact of regular relaxation training on the cardiac autonomic nervous system of hospital cleaners and bank employees
}

\author{
by Helli Toivanen, MSc, ${ }^{1}$ Esko Länsimies, MD, ${ }^{2}$ Veikko Jokela, MSc, ${ }^{3}$ Osmo Hänninen, MD ${ }^{1}$
}

\begin{abstract}
TOIVANEN H, LÄNSIMIES E, JOKELA V, HÄNNINEN O. Impact of regular relaxation training on the cardiac autonomic nervous system of hospital cleaners and bank employees. Scand J Work Environ Health 1993;19:319-25. The work-related strain of 50 female hospital cleaners and 48 female bank employees was recorded during a period of rationalization in the workplace, and the effect of daily relaxation to help the workers cope was tested. The subjects were arranged into age-matched pairs and randomly allocated into intervention and reference groups. The intervention period lasted six months. The relaxation method was brief and easily introduced as an alternative break in the workplace. Each training session lasted $15 \mathrm{~min}$. A microcomputer-based system was used to record heart rate variability in response to quiet breathing, the Valsalva maneuver, deep breathing, and active orthostatic tests. Cardiac reflexes indicated that occupational strain (especially of a mental nature) caused the functioning of the autonomic nervous system to deteriorate. Regular deep relaxation normalized the function and improved the ability to cope.
\end{abstract}

Key terms: alternative break, coping, heart rate variability, occupational strain.

Occupational stress and burnout have become serious problems in today's society. Psychosomatic symptomatology and early retirement because of disability are common, especially in predominantly caring and service vocations among women.

Female auxiliary work in general, and the work of hospital cleaners in particular, is physically demanding (1). In addition, there is a real discrepancy between physical capacity and the output expected of (aging) women in physical occupations; and this situation leads to increasing symptoms, both of a physical and mental nature (2). Working on the lowest level of the occupational hierarchy also creates stress on cleaners (3).

In offices time pressure, precision demands, role conflicts, ergonomic shortcomings, and relationships with customers can be stressing (4). In the Finnish banking sector, female workers belong to the lowest personnel level (>90\%), while men predominantly make up the managing class. The possibilities for better salaries, in-bank training, and career advancement are considerably worse for women than for their male colleagues (5).

This study was conducted during a period of workplace rationalization due to serious economic circum-

1 Department of Physiology, University of Kuopio, Kuopio, Fintand.

2 Department of Clinical Physiology, University of Kuopio, Kuopio, Finland.

3 Automatic Data Processing Center, University of Kuopio, Kuopio, Finland.

Reprint requests to: Ms H Toivanen, Department of Physiology, University of Kuopio, PO Box 1627, FIN-70211 Kuopio, Finland. stances in Finland. An economic crisis was especially the case in Finnish banks and hospitals, both of which suffered extensive cutbacks, such as a decrease in activities, a paring of expenses, and a reduction in staffing levels. The occupational future of workers became insecure, and fellow workers could be conceived as rivals. The work load of the continuously decreasing number of employees at each workplace was increasing. In addition, in bank offices, customers poured out their discontent with high-level banking policy to the clerks.

Constant strain in the absence of adequate strategies for coping is known to lead to disease $(6,7)$. Daily stress, especially if self-esteem is low, can cause behavioral changes, acute or chronic psychological reactions, physiological responses such as aches and frequent flu, depressed immune function, decreased work ability, and an increase in work-related diseases $(8-10)$.

Because there are many reports indicating that relaxation might lessen stress reactions (11-15), we have tested the use of an easy relaxation program as a method of coping. The method was designed to be so easy that it could be considered as a possible alternative to coffee and smoking breaks in the workplace.

The purpose of the study was to measure the workrelated strain of hospital cleaners and bank employees during a stressful period in their work situation from recordings of heart rate variability in cardiac autonomic nervous system function tests and to test the effect of daily relaxation as a method of coping. To determine whether people can maintain a daily relaxation practice on their own, or whether regular support is needed, we left a portion of the subjects 
alone with their exercises, while others were supported by guided meetings throughout the six months of the intervention period.

\section{Subjects and methods}

\section{Subjects}

Fifty hospital cleaners and 48 bank employees, all women, gave their informed consent to participate in the study, which was approved by the Ethical Committee of the University of Kuopio. The recruitment of the subjects occurred in a normal occupational meeting in both workplaces. The workers were informed about the project and its aims, methods, and intervention, after which the potential volunteers filled out enrollment forms. All of the willing 48 bank employees were accepted. Two hospital cleaners were excluded because of heart problems, and 10 were deleted by lottery in order to restrict the number of the hospital group to 50. According to the information provided on the enrollment forms, none of the 98 subjects had any major health problems.

Because the age range of the participants was 23-60 years and because autonomic nervous system (ANS) functions are known to be age dependent (16), the subjects were arranged (separately within each occupation) into age-matched pairs, one member of the pair being randomly appointed to the intervention group and the other entering the reference group.

All the referents continued in the study to the end. Two members of the hospital intervention group and one member of the bank intervention group withdrew for personal reasons.

\section{Intervention}

The intervention period lasted six months. The intervention method (17) was an easily learned relaxation exercise performed while sitting in an ordinary chair. Each training session lasted $15 \mathrm{~min}$ and consisted of deep breathing exercises $(2 \mathrm{~min})$, forced tension and relaxation of the abdominal muscles (3 $\min$ ), and deep relaxation as the subject focused on her gradually calming breathing. (10 min). The subjects were advised to repeat the training daily.

We also wanted to determine how easy it was to maintain this kind of daily training for a longer period, with or without regular support, and without any special personal interest, and whether the difference in the training practices was reflected in the measured results. To support the motivation of the hospital intervention group, the relaxation program was performed in guided joint meetings organized during workhours in the hospital three times a week throughout the entire intervention period. On other days the subjects were encouraged to train alone at home. The bank intervention group was taught the same program in four training sessions, after which they were left alone with their exercises but urged to maintain them on a regular basis.

In addition, the subjects of the intervention groups were encouraged to lower their shoulders and to relax themselves whenever they remembered, especially at night just before falling asleep. They were also asked to document their daily exercises. The reliability of the reports was emphasized.

\section{Measurement of cardiac autonomic nervous function}

In the beginning there were measurements designed to familiarize the subjects with the techniques, and directly after them measurement I was performed. Measurement II followed after three months, and measurement III after six months.

Both the measurement protocol and the age-related reference values for the cardiovascular ANS function tests were taken from Finnish standards $(18,19)$. The test conditions were kept peaceful and pleasant. The subjects were instructed not to have meals, drink coffee, tea or cola drinks, or smoke during the $4 \mathrm{~h}$ preceding the measurements, and to abstain from alcohol during the two preceding days. The phase of the menstrual cycle (or the menopausal status) of each subject was checked at every measurement.

A microcomputer-based system (20) for noninvasive monitoring of heart rate intervals (RRI) was used. The analyses of the recordings were performed automatically by the attached software (with the possibility of correction in the case of abnormal QRS complexes). Three surface electrodes were used. One was placed under each clavicle and the third at the point of V5-V6 of standard chest leads. Electrocardiograms were recorded for 2 min during four different tests as follows (18):

Test 1. Quiet breathing with breathing cycles (expiration + inspiration) of $5 \mathrm{~s}$ in a sitting position. Standard deviations of the RRI (RRI-SD) were calculated.

Test 2. Valsalva maneuver: blowing for $15 \mathrm{~s}$ through a mouthpiece attached to a manometer and maintaining a pressure of $40 \mathrm{~mm} \mathrm{Hg}(\approx 5.32 \mathrm{kPa})$ while sitting. The following two ratios were counted: (i) tachycardia ratio (TR) = shortest RRI during blowing : mean RRI during resting before blowing and (ii) Valsalva ratio $(\mathrm{VR})=$ longest RRI after blowing : shortest RRI during blowing.

Test 3. Deep breathing in a sitting position, deep breathing at a rate of six breaths per minute. The deep breathing difference (DBD) was calculated as the mean of four successive 10-s breathing cycles: DBD $=$ maximum instantaneous heart rate - minimum instantaneous heart rate. 
Test 4. Active orthostatic test. Before the recordings, the subject rested in the supine position for $5 \mathrm{~min}$. The maximum:minimum ratio $(\mathrm{M}: \mathrm{M})$ was calculated as follows: $\mathrm{M}: \mathrm{M}=$ longest $\mathrm{RRI}$ after standing up : shortest RRI after standing up.

\section{Questioning of work factors}

At measurement III, when the increasing occupational demands had become obvious due to the cutbacks, a small inquiry was made to obtain a better understanding of the work situation of the subjects.

The bank subjects were interviewed at measurement III about their work. The discussions dealt with current items, such as the relationship with customers, the atmosphere of the workplace, their occupational future in the bank, likes and dislikes, overtime work, feelings of tiredness, working post and status of each subject (from "low-level managers" or "better" posts in administrative and business consulting offices to "crowded low-level service on the ground floor").

The hospital subjects completed a small questionnaire concerning current feelings about their occupational future, likes and dislikes, the relationships between the cleaners, how the other hospital staff seemed to value cleaners and their work, positive and negative feedback, mental and physical strain of the work, and their perceived personal health.

\section{Statistical analysis}

The statistical examination of the measured values was based on the age-related Finnish reference values (in five-year intervals) developed by Piha (18, 19). The theoretical "expected values" between the "normal" limits (figure 1), two-sided 80\% (0.10 and 0.90 ) tolerance limits from Piha's data, were the values to which the measured results were compared $(18,19)$.

Increasing age attenuates the cardiac ANS function and narrows the intervals of reference values for most parameters $(16,18,21,22)$. The same tendency was also seen in this study (figure 1). This was the reason why the measured values of the subjects of different ages could not be counted together into group means. To avoid the weighting of the values of the younger subjects in the means, the primary measured data were transformed into standard deviations (SD) from the age-related "expected values" (figure 1). The group means of table 1 were calculated from these SD results. Thus the smaller the group mean, the nearer the results were to the "expected values" (and the "better" the results). Correspondingly, the greater the group mean, the longer the average distance from the "expected values" (and the "worse" the results).

Because of the skewedness of the distribution, and because of the use of the reference values, logarithmic transformations were performed for the results of the quiet breathing test and the Valsalva ratio, and the maximum:minimum ratios of the active orthostatic test. Deep breathing differences (DBD) were transformed as follows: $y=$ DBD raised to the power of 0.7 (18). The statistical comparison of the changes in the group means (reference group versus intervention group) from measurement I to measurement III was done with a multivariate analysis of variance (MANOVA) of repeated measures (23), or the group means of the reference group and intervention groups were compared with the use of the $t$-test at measurement III (table 1). The paired t-test was also used to test the significance of the changes in the means of each group (separately) from one measurement to the next.

The influence of the menstrual cycle and menopause on the results of the ANS function tests were examined by a two-way analysis of variance.
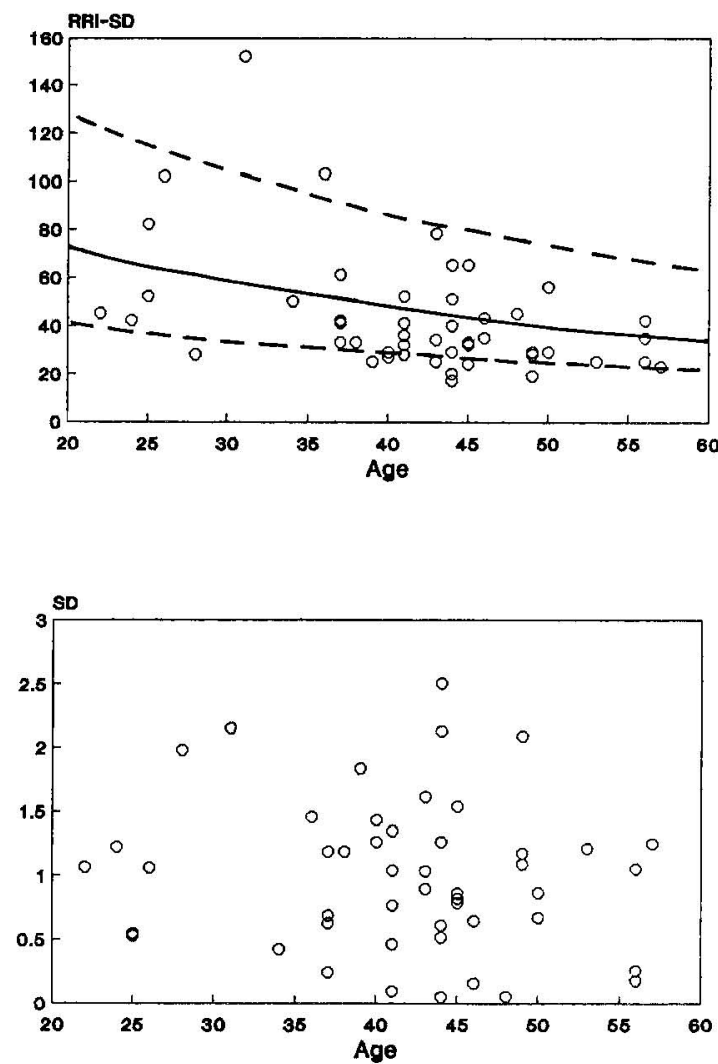

Figure 1. Upper figure: unchanged measured values of the standard deviation of the heart rate intervals (RRI-SD) as milliseconds in the quiet breathing test plotted against age in measurement $I$ of the hospital cleaners. The middle line shows the age-related "expected values." The two broken lines are the limits of the "normal values." The influence of age and the reduction of the interval between the upper and lower "normal" reference values is evident. Lower figure: values of the upper figure transformed into standard deviations (SD) from the "expected values" (= the 0 level) so that the measured results of the subjects of different ages can be compared. 
Table 1. Results of the function tests of the cardiac autonomic nervous system as standard deviations from the age-related reference values - group means for measurements I, II and III. (Direction of the group mean changes between I and II and $\mathrm{I}$ and III: + = towards the "expected values", $-=$ away from the "expected values", MANOVA = multivariate analysis of variance, $\mathrm{RRI}=$ heart rate interval)

\begin{tabular}{|c|c|c|c|c|c|c|c|c|c|c|c|c|c|c|c|c|}
\hline \multirow{3}{*}{ Function test } & \multicolumn{8}{|c|}{ Hospital cleaners } & \multicolumn{8}{|c|}{ Bank employees } \\
\hline & \multicolumn{3}{|c|}{ Reference group } & \multicolumn{5}{|c|}{ Intervention group } & \multicolumn{3}{|c|}{ Reference group } & \multicolumn{5}{|c|}{ Intervention group } \\
\hline & 1 & 11 & III & I & 11 & III & P.value & Test & 1 & II & III & 1 & II & III & P-value & Test \\
\hline $\begin{array}{l}\text { Quiet breathing } \\
\text { testa }\end{array}$ & 0.71 & $0.64(+)$ & $0.86(-)$ & 1.09 & $0.79(+)$ & $0.92(+)$ & 0.215 & MANOVA & 1.10 & $0.89(+)$ & $0.99(+)$ & 0.89 & $0.82(+)$ & $0.96(-)$ & 0.794 & t-test \\
\hline $\begin{array}{l}\text { Valsalva ratio } \\
\text { of the Valsalva } \\
\text { maneuverb }\end{array}$ & 0.66 & $0.67(-)$ & $0.97(-)$ & 0.88 & $0.69(+)$ & $0.62(+)$ & $0.001^{*}$ & "MANOVA & 0.76 & $0.92(-)$ & $0.92(-)$ & 0.77 & $0.63(+)$ & $0.51(+)$ & $0.037^{*}$ & MANOVA \\
\hline $\begin{array}{l}\text { Tachycardia } \\
\text { ratio of the } \\
\text { Valsalva } \\
\text { maneuverc }\end{array}$ & 0.53 & $0.49(+)$ & $0.73(-)$ & 0.63 & $0.57(+)$ & $0.43(+)$ & $0.007^{*}$ & "MANOVA & 0.57 & $0.62(-)$ & $0.86(-)$ & 0.68 & $0.69(-)$ & $0.65(+)$ & 0.071 & MANOVA \\
\hline $\begin{array}{l}\text { Deep breathing } \\
\text { differenced }^{\text {ding }}\end{array}$ & 0.52 & $0.75(-)$ & $0.75(-)$ & 0.81 & $0.61(+)$ & $0.78(+)$ & $0.046^{*}$ & MANOVA & 0.92 & $0.90(+)$ & $1.06(-)$ & 0.69 & $0.61(t)$ & $0.60(+)$ & $0.021^{*}$ & t-test \\
\hline $\begin{array}{l}\text { Maximum: } \\
\text { minimum ratio }\end{array}$ & 0.82 & $0.72(+)$ & $0.63(+)$ & 0.88 & $0.86(+)$ & $0.71(+)$ & 0.800 & MANOVA & 0.91 & $0.78(+)$ & $0.87(+)$ & 1.01 & $0.79(+)$ & $0.82(+)$ & 0.565 & MANOVA \\
\hline
\end{tabular}

Since the questionnaire about work experiences was only examined at the end of the follow-up, these results were not included to the statistical calculations, but were kept merely as background information relating to occupational stress.

\section{Results}

The results of the ANS function tests are shown as group means in table 1. The greater the group mean, the longer the general deviation of the measured values from the "expected values" and the "worse" the results. Consequently, the smaller the group means, the "better" the results.

Generally, the test results of the referents deviated further (-) from the "expected values" in the two follow-up measurements. The change of the mean of the deep breathing difference in the hospital reference group from 0.52 to 0.75 between measurements I and III was statistically significant $(P=0.024)$, as was that of the tachycardia ratio of the bank referents from 0.57 to $0.86(\mathrm{P}=0.027)$.

In the intervention groups the measured values changed generally towards $(+)$ the "expected values" during the intervention. In the hospital staff group, the change in the group means of the quiet breathing test and the Valsalva ratio towards the "expected values" between measurements I and II was statistically significant, with P-values of 0.042 and 0.025 , respectively, as was the change of the Valsalva ratio of the bank group $(P=0.022)$. The changes in the group means for the Valsalva and tachycardia ratios towards the "expected values" in the hospital intervention group between measurements I and III were also significant $(\mathrm{P}=0.012$ and $P=0.040$, respectively), as was that of the Valsalva ratio in the bank intervention group $(\mathrm{P}=0.007)$.

Comparison of the development of the group means (the reference groups verses the intervention groups) according to the MANOVA of repeated measures, or the comparison of the group means at measurement III by the t-test, is shown as P-values in table 1 . The different development of the means of the two hospital groups from measurements I to III is clear. For the bank subjects it was more modest. The results of measurement II represented levels between measurements I and III.

The importance of motivational support was evident. Nearly all of the members of the hospital intervention group participated in the joint meetings regularly during their workdays. They enjoyed their allowable extra breathing spaces in the middle of strenuous days. Their diary notes about their exercises were also regular and appeared to be reliable. According to them, the total training compliance of the hospital subjects was good throughout the sixmonth follow-up. Evidently, the very positive attitude of the cleaning department also influenced their motivation. For instance, all the time needed for participation in the project, including both the measurements and the continuous relaxation meetings of the intervention group, was included in the worktime of the subjects.

The bank subjects were also eager to begin the project and to learn the relaxation method. However, they were not given the regular training support. Thus, already after a couple of weeks, some of them 
found that they were no longer able to maintain regular training. They felt that the "duty" to relax was in itself stressful. In addition, only some of them were able to keep regular diaries.

According to the reports, some of the bank subjects continued rather regular relaxation sessions for the first half of the intervention period, but not for the final half. They felt that the worsening economic situation in the banking business demanded their attention; they had "more important things" to do, for instance, acquiring more qualifications required for competition for the fewer vacancies. Only a few members of the bank intervention group practiced relaxation training regularly throughout the six months. However, even their measured ANS results were modest, as were the results of the few hospital subjects who preferred to train alone at home without the support meetings. Apparently it is not easy to maintain any extra daily behavioral routine without regular support, and it also seems that without regular guidance, people do not realize how deep relaxation can and should be performed. Deep relaxation is really something other than silent sitting in a chair.

Menstrual cycle and menopause had no significant influence on the test results of the cardiac ANS function.

Work factors were regarded in essentially the same way in both the reference and intervention groups. Most of the subjects, both in the bank and in the hospital, were very worried about their future employment, and only a few were positive in this respect. In the hospital group the perceived strain varied according to the department, the direct supervisor, the attitudes of the other hospital staff, and human relations. Most of the bank subjects did not like their work as much as before, and they regarded overtime as particularly stressful. As expected, the extent of the perceived distress varied according to the work post and its status.

\section{Discussion}

Both the bank employees and the hospital cleaners experienced psychophysiological distress in their occupations during this time of rationalization in the workplace. Mental stress seemed to influence the health of the subjects when measured as heart rate variability in the cardiac ANS function tests. Workrelated strain increased during the follow-up (in the referents). However, the easily learned 15-min relaxation method employed in this study, when repeated regularly, was sufficiently effective to preserve the health of the subjects by normalizing cardiac autonomic functions. Continuous motivational support seemed to be needed to optimize the effects of the training. Regular guided relaxation meetings and an encouraging attitude on the part of management greatly strengthened the training motivation of the subjects.
The cardiac ANS function tests used in this study are widely accepted as reliable and reproducible measuring methods $(18,24)$. A combination of tests provides comprehensive and reliable information about the function of the cardiac ANS $(18,25)$. The effect of relaxation in this study was the most evident when tested by the Valsalva maneuver (Valsalva and tachycardia ratios) and deep breathing difference. The reliability of these tests is good in the sense that correct performance during recordings is easy to control. The quiet breathing test and the orthostatic test were not as sensitive.

At the beginning of the study the cleaning department of the hospital had recently been designated as a self-reliant productivity unit. Preparations were underway to allow for open competitive bidding with large and experienced commercial cleaning companies for the contract to clean the hospital in the future. Cutbacks in costs with resulting layoffs had begun, which alarmed the workers. Because the hospital subjects felt they needed any possible support, they welcomed the project warmly.

The study with the hospital subjects started in the autumn and finished in the spring. The measured values of the referents deviated further from the "expected values" the longer the time from the previous summer and vacations. This finding was regarded as evidence of increased strain and tiredness, cumulated during the working winter, and also possibly influenced by the initiated saving actions and insecurity.

The detailed work-related stress factors of the hospital cleaners varied from department to department, social relationships $(26,27)$ and low self-esteem (3) being evidently the most influential factors. The wellor ill-being of the workers seemed to be dependent on this type of mental factor. Thus improving the psychological aspects of the work environment might be a possible means with which to promote the psychophysiological fitness of workers, and their productivity as well (27).

The intervention with the bank subjects began in the beginning of March and finished in the autumn. Initially a nationwide bank strike had just ended and the sense of solidarity among the employees was great. But those feelings changed quickly to alarm during the spring (and the study). The following summer was the first during which temporary workers were not used to replace workers during vacations. At the same time cutbacks and layoffs started in the bank. Many threatening rumors were circulating and no one knew what lay ahead in the autumn. This situation was reflected also in the test results. Despite the fact that summer and vacations had not been over very long at the end of the follow-up in the autumn, most of the group means of the bank referents were at their worst in measurement III.

In all, it has been suggested that the financial savings demanded by current economic conditions are being carried out in worklife at the expense of hu- 
man health (28). Occupational distress which hampers health is a loan from human resources and must be paid back later. The most alarming aspect is that it seems to drag on and on.

The regular daily practice of relaxation normalized the cardiac ANS function of the subjects of the intervention groups in this study, especially in the hospital group. These results are in accordance with those of many other studies (11-15) and suggest that relaxation might be an effective means of lessening psychosomatic strain. Nevertheless, the "efficacy" of relaxation seems to demand determination and self-discipline (with positive attitudes) from the trainer, as well as practical support from management. Coherently organized short relaxation breaks in workplaces, such as the 15-min joint meetings for guided relaxation practice in this study, might mean an inexpensive, but proved effective means of enhancing productivity (28). No costly equipment or much time is needed (since there are coffee and smoking breaks anyway), and relaxation provides a return for the time invested in the form of better psychophysiological well-being among the employees $(28,29)$. The subjects of the intervention groups reported that, during the project, their psychosomatic symptoms diminished and their morale improved (28).

Learning the skill of deep relaxation seems to require a long training period. The duration of the intervention period of the present study was rather short. The results of the intervention group were better after six months of regular relaxation than after three months of training. Perhaps still better results would have been possible after a longer period of training, at least with those subjects who seemed to learn relaxation rather slowly. In all, it seems that relaxation should be repeated deeply and regularly over a rather long period to optimize its psychosomatic benefits. However, after the skill has been learned, it can be utilized anytime and anywhere within a few seconds.

Although it seems obvious that stress management programs effectively support the psychosomatic health of workers, there still remains one noteworthy issue. If we assume that occupational strain and related health problems originate (mainly or partly) from work factors $(9,30,31)$, the real improvements should be directed also towards these factors $(30,31)$, at least as a long-term goal. Even if relaxation and the related methods may be effective, their role should be seen primarily as a supportive health care measure. But even before any reconstruction of work as recommended by Karasek \& Theorell (31), relaxation and other stress management methods can offer, as such, reasonable possibilities to support both the health of the workers and their productivity (28). The follow-up period of our study was short, the groups were rather small, and the representativity of the sample was difficult to evaluate. These aspects restrict the possibilities to draw general conclusions.
However, we regard the results as promising. We believe that (mental) occupational stress deteriorates the cardiac ANS function (and health), and regular deep relaxation can normalize it. An encouraging attitude on behalf of management and practical support with training seem to be needed to optimize the relaxation benefits at work.

\section{Acknowledgments}

This study has been supported by the Finnish Ministry of Education and by the Foundation of Signe and Ane Gyllenberg.

The authors are grateful to Dr P Helin for his advice and to S Kostian, RN, and P Leevik, RN, for the data collection.

\section{References}

1. Huuhtanen P, Nygård C-H, Tuomi K, Eskelinen L, Toikkanen J. Changes in the content of Finnish municipal occupations over a four-year period. Scand J Work Environ Health 1991;17 suppl 1:48-57.

2. Eskelinen L, Toikkanen J, Tuomi K, Mauno I, Nygård C-H, Ilmarinen J. Symptoms of mental and physical stress in different categories of municipal work. Scand J Work Environ Health 1991;17 suppl 1:82-6.

3. Perkka-Jortikka K. Sosiaalinen hyvinvointi ja yhteisöllisyys työssä [Social well-being and communality in work: a study of the everydayness in white-collar work in the 1980's in Finland] [dissertation]. Tampere (Finland): University of Tampere, 1992. (English summary.)

4. Kalimo R. Psyykkiset ja epämääräiset somaattiset oireet työterveysongelmina [Psychological and unspecific somatic syndromes as indicators of work-related health impairment]. Työterveyslaitoksen tutkimuksia 1985;4:367-84. (English summary.)

5. Pankkitoimihenkilöliitto. Pankkitoimihenkilöliiton jäsentutkimus [The inquiry made among the members of the bank employees' union]. Helsinki: Pankkitoimihenkilöliitto, 1982. (English summary.)

6. Plaut SM, Friedman SB. Psychosocial factors in infectious diseases. In: Ader R, ed, Psychoneuroimmunology. San Diego, CA: Academic Press, 1981:3-26.

7. Rose RJ. Familial influence on cardiovascular reactivity to stress. In: Matthews KA, Weiss SM, Detre T, Dembrowski TM, Falkner B, Msnuck SB, et al, ed. Handbook of stress, reactivity, and cardiovascular disease. New York, NY: John Willey \& Sons Inc, 1986: 259-74.

8. Irwin $\mathrm{J}$, Livnat $\mathrm{S}$. Behavioral influences on the immune system: stress and conditioning. Prog Neuropsychopharmacol Biol Psychiatry 1987;11(2-3):137-43.

9. De Longis A, Folkman S, Lazarus RS. The impact of daily stress on health and mood: psychological and social resources as mediators. J Pers Soc Psychol 1988; 54(3):486-95.

10. Ilmarinen J, Tuomi K, Eskelinen L, Nygård C-H, Huuhtanen P, Klockars M. Background and objectives of the Finnish research project on aging workers in municipal occupations. Scand J Work Environ Health 1991;17 suppl 1:7-11.

11. Benson HJ, Beary JF, Carol MP. The relaxation response. Psychiatry 1974;37:37-46.

12. Peters RK, Benson HJ, Peters JM. Daily relaxation response breaks in a working population: II. effects on blood pressure. Am J Public Health 1977;67(10):9549. 
13. Patel C, Marmot MG. Stress management, blood pressure and quality of life. J Hypertens Suppl 1987;5(1): S21-8.

14. Helin $P$, Hänninen $O$. Relaxation training affects success and activation on a teaching test. Int $\mathrm{J}$ Psychophysiol 1987;5:275-87.

15. Helin P. Psychophysiological activation during performance and competition and the effects of relaxation training and running exercise [dissertation]. Kuopio (Finland): University of Kuopio, 1988.

16. Wieling W, van Brederode JFM, de Rijk LG, Borst C, Dunning AJ. Reflex control of heart rate in normal subjects in relation to age: a data base for cardiac vagal neuropathy. Diabetologia 1982;22:163-6.

17. Joshi KS. Yogic pranayama; breathing for long life \& good health. Delhi (India): Orient Paperbacks, 1986.

18. Piha SJ. Cardiovascular autonomic function tests: response in healthy subjects and determination of the age-related reference values [dissertation]. Turku (Finland): University of Turku, 1988.

19. Piha SJ. Cardiovascular reflex tests and the resting heart rate at night and during testing. Clin Physiol $1992 ; 12: 225-7$.

20. Tahvanainen K, Länsimies E, Tikkanen $P$, Hartikainen J, Kärki T, Lyyra T, et al. Microcomputer-based monitoring of cardiovascular functions in simulated microgravity. Adv Space Res 1992;12:227-36.

21. O'Bien IAD, O'Hare P, Corrall RJM. Heart rate variability in healthy subjects: effect of age and the derivation of normal ranges for tests of autonomic function. Br Heart J 1986;55:348-54.

22. Bergström B, Lilja B, Rosberg K, Sundkvist G. Autonomic nerve function tests: reference values in healthy subjects. Clin Physiol 1986;6:523-8.

23. Winer BJ. Statistical principles in experimental design. New York, NY: McGraw Hill, 1971.
24. Ewing DJ, Martyn CN, Young RJ, Clarke BF. The value of cardiovascular autonomic function tests: 10 years experience in diabetes. Diabetes Care 1985;8:491-8.

25. Pearsson A, Solders G. R-R variations, a test of autonomic dysfunction. Acta Neurol Scand 1983;67:28593.

26. Kalimo R. Stress in work: conceptual analysis and study on prison personnel. Scand $J$ work Environ Health 1980;6 suppl 3:1-124.

27. Sievers K, Klaukka T, Mäkelä M. TULES-vuori matalaksi: tuki- ja liikuntaelinsairauksien kansanterveydellinen merkitys Suomessa sekä suosituksia ongelman ratkaisemiseksi [What should be done about the growing problem of musculoskeletal disorders in Finland?] Helsinki: Social Insurance Institution, 1990. (Kansaneläkelaitoksen julkaisu; no ML:96.) (English summary.)

28. Fielding JE. Work site stress management: national survey results. J Occup Med 1989;31:990-5.

29. Fiedler N, Vivona-Vaughan E, Gochfeld M. Evaluation of a work site relaxation training program using ambulatory blood pressure monitoring. J Occup Med 1989;31:595-602.

30. Lukinmaa A. Lanneselkäsairaus biopsykososiaalisena häiriönä. Kontrolloitu hoitotutkimus ja kustannusvaikuttavuusanalyysi [Low-back pain as a biopsychosocial problem: a controlled clinical trial and cost-effectiveness analysis]. Helsinki: Social Insurance Institution, 1989. (Kansaneläkelaitoksen julkaisu; no ML:90.) (English summary.)

31. Karasek R, Theorell T. Healthy work: stress, productivity, and the reconstruction of working life. New York, NY: Basic Books Inc, 1990.

Received for publication: 2 October 1992 